\title{
2-Aminoethoxydiphenylborane Is an Acute Inhibitor of Directly Photosensitive Retinal Ganglion Cell Activity In Vitro and In Vivo
}

\author{
Sumathi Sekaran, ${ }^{1}$ Gurprit S. Lall, ${ }^{2}$ Katherine L. Ralphs, ${ }^{3}$ Adrian J. Wolstenholme, ${ }^{3}$ Robert J. Lucas, ${ }^{2}$ Russell G. Foster, ${ }^{1}$ \\ and Mark W. Hankins ${ }^{1}$ \\ ${ }^{1}$ Circadian and Visual Neuroscience Group, University of Oxford, Wellcome Trust Centre for Human Genetics, Oxford OX3 7BN, United Kingdom, ${ }^{2}$ Faculty \\ of Life Sciences, University of Manchester, Manchester M13 9PT, United Kingdom, and ${ }^{3}$ Department of Biology and Biochemistry, University of Bath, Bath \\ BA2 7AY, United Kingdom
}

The mammalian retina contains directly photosensitive retinal ganglion cells (RGCs), which use the photopigment melanopsin. The generation of mice lacking melanopsin has been invaluable in elucidating the function of these cells. These animals display deficiencies in circadian photoentrainment, the pupil light reflex, and the circadian regulation of the cone pathway. Interpreting the results from such gene knock-out models is always complicated by neuronal plasticity and the potential for restructuring of neuronal networks. Until now, the study of photosensitive RGCs has lacked an acute inhibitor. 2-Aminoethoxydiphenylborane (2-APB) is an antagonist at IP ${ }_{3}$ receptors and an inhibitor of canonical transient receptor potential ion channels (TRPCs). Here, we show that 2-APB is an extremely potent in vitro inhibitor of the photosensitive RGCs and that its effect is independent of store-dependent $\mathrm{Ca}^{2+}$ release. The identification of canonical TRPC6 and TRPC7 ion channels in melanopsin-expressing ganglion cells suggests that 2-APB may act directly on a TRPC ion channel. Importantly, using the pupil light reflex as a functional assay, we show that 2-APB inhibits photosensitive RGC activity in vivo. Collectively, our data further elucidate the phototransduction pathway in the photosensitive RGCs and demonstrate that 2-APB can be used to silence activity in these cells both in vitro and in vivo.

Key words: 2-aminoethoxydiphenylborane; melanopsin; retinal ganglion cell; TRPC6; TRPC7; pupil light reflex

\section{Introduction}

A small subset of mammalian retinal ganglion cells (RGCs) (1-3\%) are directly photosensitive (Berson et al., 2002; Sekaran et al., 2003). These cells express melanopsin (Hattar et al., 2002), a G-protein-coupled receptor protein that forms a fully functional photopigment in expression systems (Melyan et al., 2005; Panda et al., 2005; Qiu et al., 2005). To assess the function of the photosensitive RGCs, mice with a targeted disruption of the melanopsin gene (Opn4) have been generated (Hattar et al., 2002; Panda et al., 2002). Opn $4^{-/-}$mice lack intrinsic light responses of ganglion cell layer neurons (Hattar et al., 2002) and exhibit deficiencies in circadian photoentrainment (Panda et al., 2002), the pupil light reflex (PLR) (Lucas et al., 2003), and circadian regulation of the cone pathway (Barnard et al., 2006). These studies have demonstrated that this small population of photosensitive RGCs provides a significant contribution to non-image-forming photic responses.

\footnotetext{
Received 0ct. 30, 2006; revised March 12, 2007; accepted March 14, 2007.

This work was supported by the Wellcome Trust and the Biotechnology and Biological Sciences Research Council. We thank King-Wai Yau and Samer Hattar for the kind gift of the melanopsin knock-out mouse line.

Correspondence should be addressed to Sumathi Sekaran, Circadian and Visual Neuroscience Group, University of Oxford, Wellcome Trust Centre for Human Genetics, Roosevelt Drive, Oxford OX3 7BN, UK. E-mail: sumathi.sekaran@eye.ox.ac.uk.

DOI:10.1523/JNEUROSCI.4716-06.2007

Copyright $\odot 2007$ Society for Neuroscience $\quad 0270-6474 / 07 / 273981-06 \$ 15.00 / 0$
}

The full functional implications of the melanopsin-expressing photosensitive RGCs are unclear. The axons of these cells project to brain regions involved in non-image-forming functions, including the suprachiasmatic nucleus and the olivary pretectal nucleus (Hattar et al., 2002). Somewhat surprisingly, they also innervate a wide range of additional targets, including the lateral geniculate nucleus, the superior colliculus, and the amygdala (Hattar et al., 2006). The use of Opn $4^{-1-}$ mice will go some way to further our understanding of photosensitive RGC outputs, but as with all knock-out models, these studies are confounded by possible neuronal restructuring during development. At present, the field lacks an acute inhibitor of photosensitive RGC activity.

The main aim of the current study was to identify a pharmacological agent that could acutely target the photosensitive RGCs. To narrow our search, we focused on canonical transient receptor potential (TRP) ion channels (TRPCs), which have been suggested to be the likely endpoint in the phototransduction pathway that couples to melanopsin on the basis of several lines of evidence. Melanopsin shows high sequence homology to invertebrate opsins (Provencio et al., 1998), which can couple to TRP ion channels (Montell, 2005). Coexpression of melanopsin with TRPC channels resulted in the generation of a functional photopigment (Panda et al., 2005; Qiu et al., 2005). Light-evoked currents in rat photosensitive RGCs can be suppressed by TRPC channel blockers (Warren et al., 2006). The results from the 
present study provide additional support for a role of TRPC channels in the phototransduction pathway of mouse photosensitive RGCs. In particular, we found that the TRPC channel inhibitor 2-aminoethoxydiphenylborane (2-APB) is a potent inhibitor of intrinsic light-evoked activity in the ganglion cell layer, both in vitro and in vivo.

\section{Materials and Methods}

All procedures were performed under United Kingdom Home Office guidelines.

Calcium imaging. Retinas from $\mathrm{C} 3 \mathrm{H}$ mice (wild type at the $r d$ locus; postnatal days $4-5$ ) and $\mathrm{C} 3 \mathrm{H} \mathrm{rd} / \mathrm{rd} \mathrm{cl}$ mice (3-6 months) were placed in a recording chamber ganglion cell side up and incubated in Ringer's solution [(in mM) $119 \mathrm{NaCl}, 2.5 \mathrm{KCl}, 1 \mathrm{KH}_{2} \mathrm{PO}_{4}, 1.3 \mathrm{MgCl}_{2}, 2.5 \mathrm{CaCl}_{2}$, 26.2 $\mathrm{NaHCO}_{3}$, and 20 D-glucose; equilibrated with $95 \% \mathrm{O}_{2} / 5 \% \mathrm{CO}_{2} ; \mathrm{pH}$ 7.4] containing $10 \mu \mathrm{M}$ fura-2 AM (Invitrogen, Paisley, UK). The fluorescent imaging technique has been described in detail previously (Sekaran et al., 2003, 2005). Briefly, the dual-wavelength $\mathrm{Ca}^{2+}$-sensitive indicator fura-2 AM was excited alternately at 340 and $380 \mathrm{~nm}$. Emitted fluorescence $(510 \mathrm{~nm})$ was captured with an intensified CCD camera every $2 \mathrm{~s}$. Retinas were stimulated at $470 \pm 20 \mathrm{~nm}\left(4.9 \times 10^{12}-2.9 \times 10^{15}\right.$ photons/ $\mathrm{s} / \mathrm{cm}^{2}$ ) interleaved between image acquisitions. Pharmacological agents were administered until two successive light-evoked responses of equivalent amplitude were obtained (maximum period of drug application was $30 \mathrm{~min}$ ). The drift in the baseline fluorescence was corrected to the prestimulus values $(\Delta F / F)$ by curve fitting. The integrated change in fluorescence during light stimulation was calculated $\left(F / \mathrm{s}^{2}\right)$. Where possible, responses from two repeated stimulations were averaged for the control and drug-treated conditions. Data are expressed as mean \pm SEM, and statistical analysis was performed with paired $t$ tests.

TRPC7 antibody generation and validation. The TRPC7 antibody was raised against a peptide corresponding to the $\mathrm{C}$-terminal 16 aa of human TRPC7 (hTRPC7) coupled to keyhole limpet hemocyanin using $0.05 \%$ $(\mathrm{v} / \mathrm{v})$ glutaraldehyde. This conjugate was used to raise a rabbit antiserum by Harlan (Bicester, UK).

HEK293 (human embryonic kidney 293) cells were transfected with one of the following constructs: full-length hTRPC7 cDNA subcloned into the pIRES2-EGFP vector (Clontech, Saint-Germain-en-Laye, France) or into pFLAG-CMV2 (Sigma, Dorset, UK), myc-tagged versions of hTRPC3 and hTRPC6, a FLAG-tagged version of TRPC1 (kind gifts from Drs. C. Montell, Johns Hopkins University School of Medicine, Baltimore, MD, and Barbara Reaves, University of Bath, Bath, UK), or the appropriate empty vectors. Cells were transfected with $4 \mu \mathrm{g}$ of plasmid DNA using Lipofectamine 2000 (Invitrogen) and incubated for 24-48 h. Cells were harvested and centrifuged. The resultant pellet was resuspended in PBS and subjected to electrophoresis on a $10 \%(\mathrm{w} / \mathrm{v})$ SDS-polyacrylamide gel. The separated proteins were transferred to a nitrocellulose membrane and probed with anti-TRPC7 (1:1000) for $2 \mathrm{~h}$. The blot was developed using the Rabbit IgG Vectastain ABC kit (Vector Laboratories, Peterborough, UK). The cells were also processed for immunocytochemistry. Plated cells were fixed in $2 \%$ paraformaldehyde (PFA), washed, and incubated in 10\% (v/v) FBS for $20 \mathrm{~min}$. Anti-TRPC7 antibody $(1: 100)$ or the antibody preabsorbed with antigen was applied for at least $1 \mathrm{~h}$. Alexa Fluor 546 conjugated goat-anti rabbit (1:200; Invitrogen) was used as the secondary antibody. Coverslips were mounted and observed with a Zeiss (Oberkochen, Germany) LSM510 confocal microscope.

Retinal immunohistochemistry. Eyes from Opn4-tauLac $Z^{+/-}$mice (mixed strain, 129/sv and C57BL/6) were removed and placed in 4\% PFA overnight and cryoprotected in $30 \%$ sucrose. The eyes were hemisected, immersed in gelatin $(7.5 \%)$ /sucrose $(10 \%)$ and flash frozen. Retinal sections $(15 \mu \mathrm{m})$ were cut on a cryostat and mounted on slides. Slides were treated with an antigen retrieval agent (1\% SDS; $5 \mathrm{~min})$, washed, and incubated in a $2 \%$ normal donkey serum blocking solution for $1 \mathrm{~h}$. Serial double antibody labeling was performed with $\alpha$ - $\beta$-galactosidase [1:1000; raised in goat (Biotrend, Cologne, Germany); secondary antibody, Alexa Fluor 568 donkey $\alpha$-goat IgG (Invitrogen)] to label the melanopsin cells and $\alpha$-TRPC1 (1:200), $\alpha$-TRPC3 (1:500), $\alpha$-TRPC4 (1:500), $\alpha$-TRPC6
(1:500; all from Alomone Labs, Jerusalem, Israel), or $\alpha$-TRPC7 (1:200) (supplemental Fig. 1, available at www.jneurosci.org as supplemental material). All TRPC antibodies were raised in rabbit (secondary antibody, Alexa Fluor 488 donkey $\alpha$-rabbit IgG). Sections were mounted in media with 4',6'-diamidino-2-phenylindole dihydrochloride (DAPI) (Vector Laboratories) and visualized with a Zeiss LSM510 confocal microscope.

Pupillometry. All measurements were restricted to the middle of the light portion of a $12 \mathrm{~h}$ light/dark cycle. The consensual PLR was recorded from dark-adapted (20 min) $\mathrm{C} 3 \mathrm{H}$ mice $70-120 \mathrm{~d}$ of age (preinjection control) (Lucas et al., 2001). Mice were anesthetized with isoflurane before intraocular injection. A glass electrode attached to a Hamilton syringe was used to inject $1 \mu \mathrm{l}$ of solution containing pharmacological agents or vehicle control ( $1 \%$ DMSO). Recovery from anesthesia was complete within minutes, and postinjection PLR recordings were made at 20 and $40 \mathrm{~min}$ time points. Light stimuli ( $480 \mathrm{~nm} ; 10 \times 10^{12}$ photons/ $\mathrm{cm}^{2} / \mathrm{s}$ ) of 1 min duration were generated using a xenon arc source transferred into an integrating sphere by an optic cable to provide illumination to the whole eye. Pupil images were digitally captured using a CCD camera and analyzed by software developed in house. After the last pupillary recording, all mice were killed ( $\sim 40 \mathrm{~min}$ after injection).

Drugs. The following drugs were used: L-(+)-2-amino-4phosphonobutyric acid (L-AP4; Tocris Bioscience, Bristol, UK); DL-2amino-5-phosphonopentanoic acid (DL-AP5; Tocris Bioscience); 2-aminoethoxydiphenylborane (Tocris Bioscience); (+)-cis-diltiazem hydrochloride (L-cis-diltiazem; Sigma); cyclopiazonic acid (Tocris Bioscience); 6,7-dinitroquinoxaline-2,3-dione (DNQX; Tocris Bioscience); flufenamic acid (Sigma); SKF96365 hydrochloride (Tocris Bioscience); and thapsigargin (Tocris Bioscience).

\section{Results}

Effect of TRPC channel inhibitors on the photosensitive RGC light response in vitro

To visualize the light responses of the photosensitive RGCs, we used $\mathrm{Ca}^{2+}$ imaging in whole-mount neonatal wild-type mouse retinas at postnatal days 4-5 (Sekaran et al., 2005) and in adult rodless coneless $(r d / r d c l)$ mouse retinas (Sekaran et al., 2003). Both models lack functional rod- and cone-based photoreception.

In neonatal mouse retinas, the voltage-gated $\mathrm{Ca}^{2+}$ channel and TRPC channel blocker $\mathrm{La}^{3+}(50$ or $100 \mu \mathrm{M})$ significantly suppressed light-evoked responses in ganglion cell layer neurons (by 33 and 37\%, respectively; $p<0.001 ; n=20$ for both). In addition, the TRPC channel blocker SKF96365 (100 $\mu \mathrm{M})$ completely abolished light-evoked activity $(p<0.05 ; n=4)$ (Fig. 1). In contrast, an inhibitor of cyclic nucleotide-gated cation channels (present in rod and cone photoreceptors), L-cis-diltiazem (30 $\mu \mathrm{M})$, had no significant effect on the light-evoked responses $(p>$ $0.05 ; n=19$ ) (Fig. 1). These results concur with published electrophysiological data (Warren et al., 2006), validating the use of $\mathrm{Ca}^{2+}$ imaging to assess photosensitive RGC light responses and confirm that TRPC channels are involved in the phototransduction pathway of these cells.

We examined the effects of another TRPC channel inhibitor, the organoborane 2-APB (Xu et al., 2005). 2-APB (100 $\mu \mathrm{M})$ completely blocked light-evoked responses in ganglion cell layer neurons within seconds of bath application $(p<0.05 ; n=5)$ (Fig. 1). Light responses recovered by $44 \pm 0.03 \%$ of the pretreatment level after washout. 2-APB is generally used in the micromolar range; however, we were surprised to find that it was also extremely potent at nanomolar concentrations (500 nM; $p<0.05$; $n=4 ; 75 \pm 0.07 \%$ recovery after wash). In the presence of $2-\mathrm{APB}$, $\mathrm{Ca}^{2+}$ wave activity in the ganglion cell layer, which is typical of the neonatal retina, was not disrupted, suggesting that this drug did not silence activity in all RGCs. $\mathrm{Ca}^{2+}$ wave activity was also maintained in the photosensitive RGCs, confirming that 2-APB was targeting the phototransduction pathway in these cells (in- 


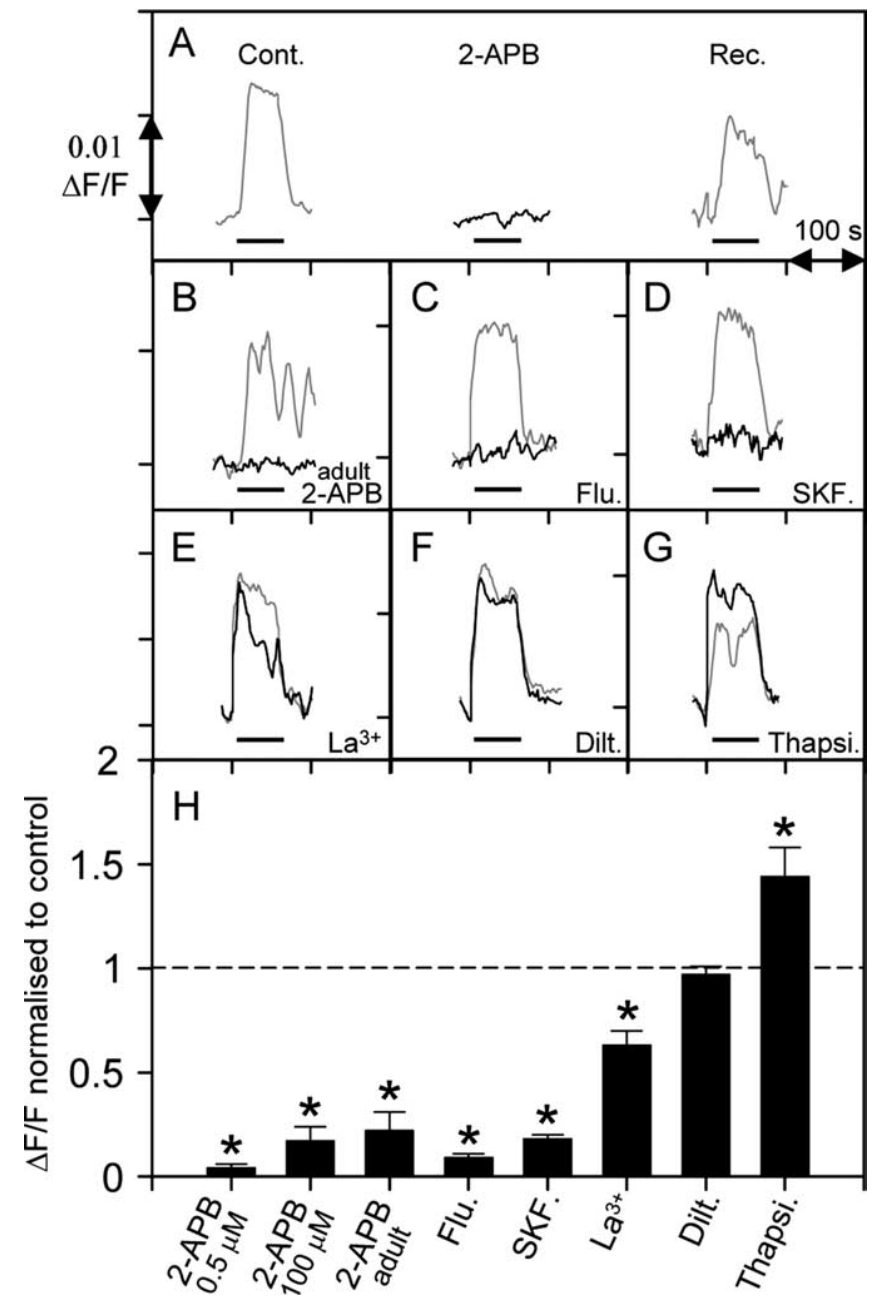

Figure 1. TRPC channel blockers inhibit photosensitive RGC activity. Representative examples of the change in fura-2 AM fluorescence in individual photosensitive RGCs in response to light stimulation ( $470 \mathrm{~nm}$; as indicated) in the presence (black) and absence (gray) of pharmacological agents. The fluorescence levels $(F, 340 / 380 \mathrm{~nm})$ were corrected to the baseline values by curve fitting and subtraction $(\triangle F / F) . \boldsymbol{A}-\mathbf{G}$, Drugs were applied to the perfusate: 2-APB $(\boldsymbol{A}$; $100 \mu \mathrm{m}$; including recovery), 2-APB adult $(\boldsymbol{B} ; 100 \mu \mathrm{M})$, flufenamate $(\boldsymbol{C} ; 100 \mu \mathrm{M})$, SKF96365 (D; $100 \mu \mathrm{M}), \mathrm{La}^{3+}(\boldsymbol{E} ; 100 \mu \mathrm{M}), \mathrm{L}$-cis-diltiazem $(\boldsymbol{F} ; 30 \mu \mathrm{M})$, and thapsigargin $(\mathbf{G} ; 5 \mu \mathrm{M})$. Each increment on the $x$-axis represents $100 \mathrm{~s}$, and each increment on the $y$-axis represents 0.01 $\Delta F / F$. $\boldsymbol{H}$, Mean change in integrated fluorescence $\left(F / s^{2}\right)$ during light stimulation after drug application. Data have been normalized to the pre-drug treatment "control" $\mathrm{F} / \mathrm{s}^{2}$ value (dashed line represents no change in fluorescence values). Significant differences relative to the control data are indicated $\left({ }^{*} p<0.05\right)$. Cont., Control; Rec., recovery; Flu., flufenamate; SKF., SKF96365; Dilt., L-cis-diltiazem; Thapsi., thapsigargin. Error bars represent SEM.

terwave interval before drug treatment, $260 \pm 17 \mathrm{~s}$; interwave interval during 2-APB application, $261 \pm 24 \mathrm{~s} ; n=8$ ). The inhibitory effects of 2-APB in the photosensitive RGCs could be duplicated in adult mice. Application of 10-100 $\mu \mathrm{M}$ 2-APB blocked inner retinal light-evoked activity in the adult $r d / r d c l$ mouse retina (Fig. 1).

2-APB was originally identified as a membrane-permeant $\mathrm{IP}_{3}$ receptor antagonist and blocker of store-operated $\mathrm{Ca}^{2+}$ entry (Maruyama et al., 1997). To determine whether the effects of 2 -APB were dependent on intracellular $\mathrm{Ca}^{2+}$ release, we depleted the stores with an inhibitor of the sarco/endoplasmic reticulum $\mathrm{Ca}^{2+}$ ATPase (SERCA). Thapsigargin $(5 \mu \mathrm{M})$ did not inhibit the light response. In fact, a significant potentiation of the lightevoked $\mathrm{Ca}^{2+}$ influx was observed $(p<0.05 ; n=11)$ (Fig. 1). A similar result was obtained with another SERCA inhibitor, cyclopiazonic acid (10 $\mu \mathrm{M}$; data not shown).

\section{Expression of TRPC channels in the retina}

The mammalian canonical TRP channels can be divided into four families based on sequence homology and pharmacological properties: (1) TRPC1; (2) TRPC2; (3) TRPC3, TRPC6, and TRPC7; and (4) TRPC4 and TRPC5 (Montell, 2005). These channels form heteromeric complexes with members of the same family (except TRPC1). 2-APB can directly inhibit the activity of many of the TRPC channel members (Trebak et al., 2002; Xu et al., 2005; Zagranichnaya et al., 2005). In an attempt to identify the TRPC channel that might be modulated by 2 -APB in the photosensitive RGCs, we examined the expression patterns of TRPC1, TRPC3, TRPC4, TRPC6 (Alomone Labs), and TRPC7 (supplemental Fig. 1, available at www.jneurosci.org as supplemental material) in the retina of adult mice heterozygous for the tauLacZ transgene targeted to the melanopsin (Opn4) gene locus (Hattar et al., 2002). A $\beta$-galactosidase antibody was used to identify the melanopsin-expressing cells.

It has been demonstrated previously in the rat retina that TRPC6 is present in the same cells that express melanopsin and that flufenamic acid, an enhancer of TRPC6 activity (Inoue et al., 2001), potentiates the light-evoked response (Warren et al., 2006). Presently, in the mouse retina, we also observed expression of TRPC6 in melanopsin-expressing neurons (Fig. 2) but found that flufenamic acid completely abolished the light-evoked response ( $p<0.001 ; n=14)$ (Fig. 1$)$. This would suggest that either the activity of TRPC6 channels in mouse photosensitive RGCs is not enhanced by this drug (Xu et al., 2005) or that these channels were not accessible to the drug. Interestingly, we observed a primarily internal distribution of TRPC6 within the melanopsin-expressing cells, possibly precluding drug accessibility. Indeed, reticular expression of TRPC6 has been noted in cultured human myometrial smooth muscle cells (Dalrymple et al., 2002). Flufenamic acid has additionally been shown to inhibit TRPC3 and TRPC7 activity (Zagranichnaya et al., 2005), and we observed colocalization of TRPC7 (but not TRPC3) with melanopsin in the mouse RGCs (Fig. 2). TRPC1 and TRPC4 were weakly expressed in the retina but did not colocalize with melanopsin expression.

\section{Effect of 2-APB on photosensitive RGC activity in vivo}

$2-\mathrm{APB}$ is an effective inhibitor of light-evoked $\mathrm{Ca}^{2+}$ influx in photosensitive RGCs in vitro in both neonatal and adult retinas. We determined whether 2-APB might be used as an inhibitor of photosensitive RGC light responses in vivo. To this end, we combined intraocular 2-APB injections with the consensual PLR in adult wild-type mice (Fig. 3). The PLR is driven by a combination of rods, cones, and photosensitive RGCs (Lucas et al., 2001, 2003; Hattar et al., 2003). To eliminate any rod and cone input, the glutamate receptor blockers DNQX (5 mM), DL-AP5 (5 mM), and L-AP4 (10 mM) were routinely included in the injected solution. Effective concentrations in the retina were calculated to be 0.01 times the applied dose based on penetration and vitreal volume. The glutamate receptor modulators had no significant effect on the amplitude of the PLR to high-irradiance stimulation when injected alone $(n=4 ; p>0.05)$ (Fig. 3). Intraocular injection of 2 -APB ( $1 \mathrm{~mm}$ ) significantly suppressed pupillary constriction relative to the preinjection control $(n=4 ; p<0.01)$. Partial recovery of the response was observed $40 \mathrm{~min}$ after injection. 


\section{Discussion}

Two main conclusions can be drawn from this study: TRPC channels carry the lightevoked conductance in photosensitive RGCs, and 2-APB, an inhibitor of TRPC channels, can be used as an effective in vitro and in vivo inhibitor of photosensitive RGC activity.

TRPC channels carry the light-evoked conductance of photosensitive RGCs TRP channels have been found to be expressed in the photoreceptor cells of several species. They were first identified in Drosophila rhabdomeric photoreceptors (Montell and Rubin, 1989; Hardie and Minke, 1992), and TRP channel homologues have also been found in limulus (Bandyopadhyay and Payne, 2004) and squid (Monk et al., 1996) photoreceptor membranes. This suggests that these channels may constitute a common endpoint in phototransduction pathways.

Because melanopsin resembles an invertebrate-like opsin (Provencio et al., 1998) and melanopsin can couple to TRPC channels in expression systems (Panda et al., 2005; Qiu et al., 2005), it has been proposed that TRPC channels may be involved in photosensitive RGC phototransduction. Presently, we show that three different TRPC channel blockers (2APB, SKF96365, and flufenamic acid) completely inhibit the light-evoked response of photosensitive RGCs, largely concurring with findings in rat retinas (Warren et al., 2006) and strengthening the case for a role for TRPC channels in the phototransduction pathway.

\section{2-APB, a potent inhibitor of}

photosensitive RGC activity

Of the TRPC channel blockers used in the present study, 2-APB was found to be extremely potent and effective at nanomolar concentrations. This drug completely inhibited inner retinal photosensitivity in neonatal and adult mice. 2-APB was originally identified as an antagonist at $\mathrm{IP}_{3}$ receptors (Maruyama et al., 1997). We showed that the effect of 2-APB was independent of store-operated $\mathrm{Ca}^{2+}$ release. In fact, depleting the $\mathrm{Ca}^{2+}$ stores potentiated the light-evoked responses, possibly as a result of the reduced $\mathrm{Ca}^{2+}$-buffering capacity of the cell. Evidence from heterologous expression studies have proposed that melanopsin may couple to a pathway, resulting in intracellular $\mathrm{Ca}^{2+}$ release (Melyan et al., 2005). However, in expression systems, the signaling pathway associated with melanopsin varies depending on the cell line used (Melyan et al., 2005;

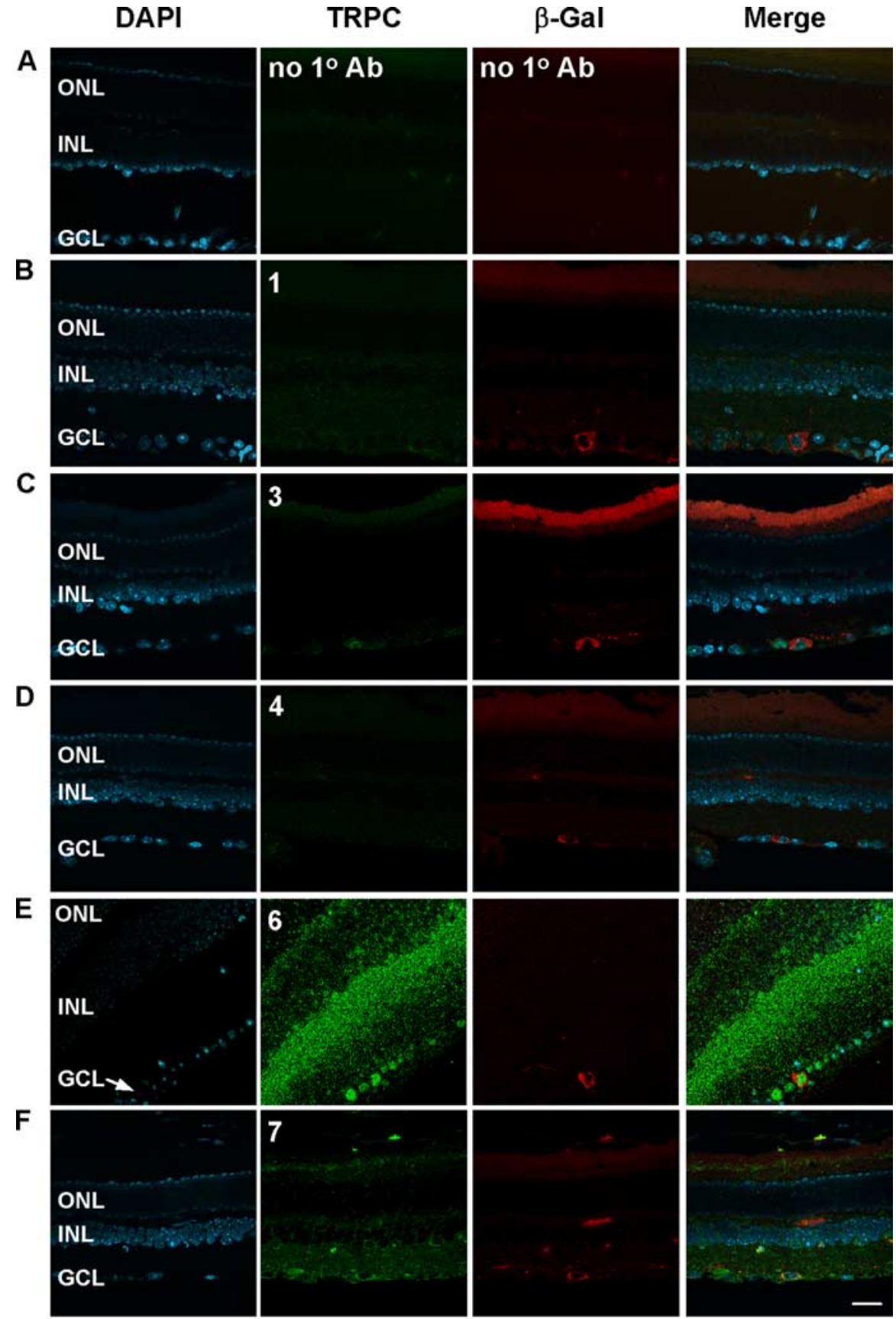

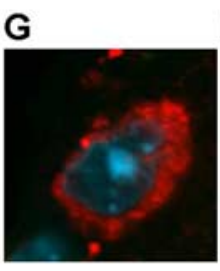

TRPC1

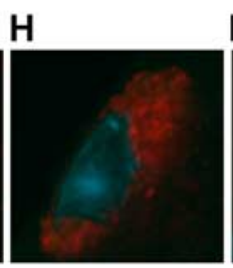

TRPC3

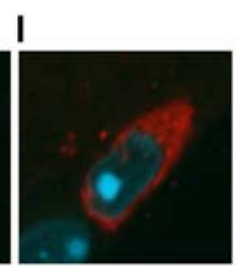

TRPC4

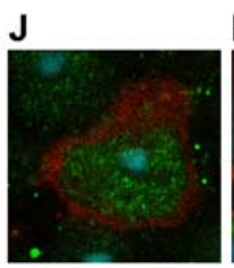

TRPC6

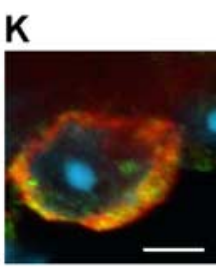

TRPC7
Figure 2. TRPC channel localization in the retina. Confocal micrographs of TRPC channel (green) and melanopsin expression in Opn4-tauLac $Z^{+/-}$mouse retinas [a $\beta$-galactosidase ( $\beta$-gal) antibody (red) was used to identify melanopsin-expressing cells]. Cell nuclei are labeled with DAPI (blue). $\boldsymbol{A}$, No staining was observed in the no primary antibody (no $\left.1^{\circ} \mathrm{Ab}\right) \operatorname{control}$ condition. $\boldsymbol{B}-\boldsymbol{D}$, $\boldsymbol{G}-\boldsymbol{I}, \operatorname{TRPC}(\boldsymbol{B}, \boldsymbol{G}), \operatorname{TRPC}(\boldsymbol{C}, \boldsymbol{H})$, and TRPC4 $(\boldsymbol{D}, \boldsymbol{I})$ were weakly expressed in the retina and did not colocalize with $\beta$-gal expression. $\boldsymbol{E}, \boldsymbol{J}, \mathrm{TRPC} 6$ was highly expressed in the plexiform layers and in many inner retinal neurons. TRPC 6 expression did colocalize with $\beta$-gal expression. $\boldsymbol{F}, \boldsymbol{K}$, TRPC7 was also expressed in the plexiform layers and many inner retinal neurons and colocalized with $\beta$-gal expression. Note that some autofluorescence was observed, particularly after excitation at $568 \mathrm{~nm}$ in the rod and cone photoreceptor cell outer segment regions ( $\boldsymbol{C}$ ) and in blood erythrocytes ( $\boldsymbol{F}$, inner plexiform layer). 0NL, Outer nuclear layer; INL, inner nuclear layer; GCL, ganglion cell layer. Scale bars: $\boldsymbol{A}-\boldsymbol{F}, 20 \mu \mathrm{m} ; \boldsymbol{G}-\boldsymbol{K}, 5 \mu \mathrm{m}$. 
A
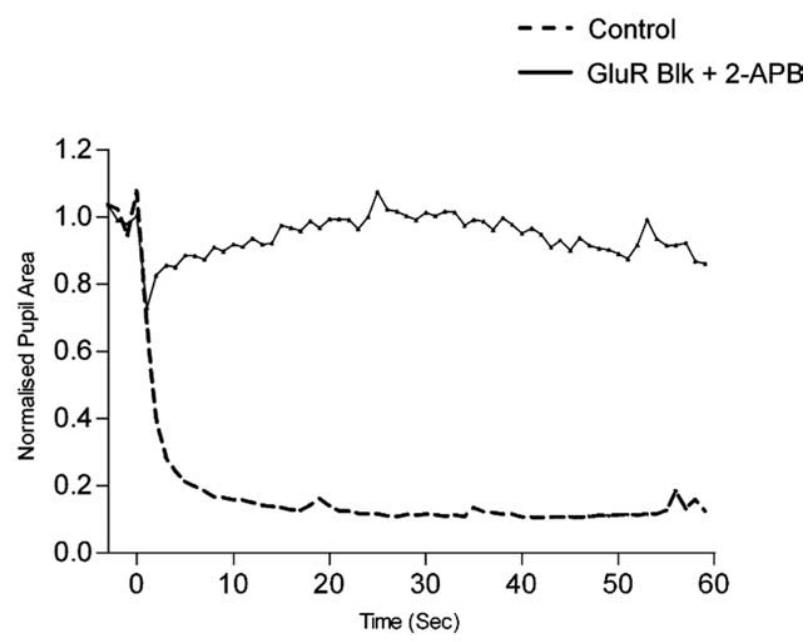

B
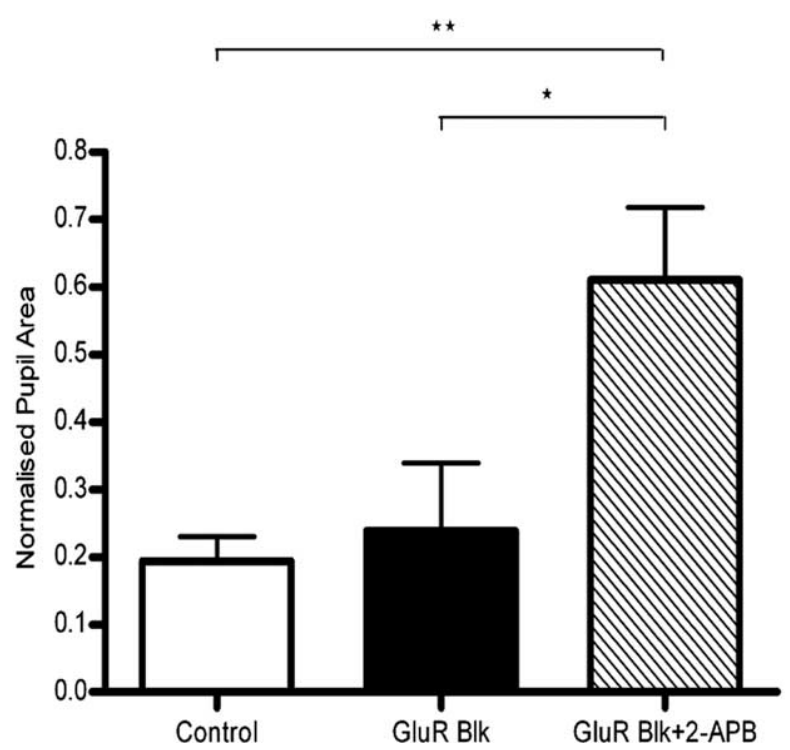

Figure 3. In vivo TRPC channel inhibition and the pupillary light reflex. $A$, Representative trace of preinjection PLR (control; dashed line) and 20 min after intraocular injection of 2-APB (1 $\mathrm{mm}$; solid line) in the presence of a glutamate receptor-blocking mixture (DNQX, $5 \mathrm{~mm}$; DL-AP5, $5 \mathrm{~mm} ; \mathrm{L}-\mathrm{AP} 4,10 \mathrm{~mm}$ ). The onset of the light stimulus is indicated below the graph. $\boldsymbol{B}$, Maximum pupil constriction for preinjection control responses and after injection of the glutamate receptor blockers alone or in combination with 2-APB. Significant differences are indicated $\left({ }^{*} p<\right.$ $\left.0.05 ;{ }^{* *} p<0.01\right)$. GluR Blk, Glutamate receptor-blocking mixture. Error bars represent SEM.

Panda et al., 2005; Qiu et al., 2005), and, as the current data suggests, may not reflect the native transduction mechanism in photosensitive RGCs.

2-APB can directly inhibit TRPC ion channels including TRPC1, TRPC3, TRPC5, TRPC6, and TRPC7 (Trebak et al., 2002; Xu et al., 2005; Zagranichnaya et al., 2005). We investigated TRPC channel expression in the mouse retina and identified members of the group 3 channels, TRPC6 and TRPC7 (but not TRPC3), in the same cells that expressed melanopsin. A differential cellular distribution of these channels was apparent, with TRPC6 primarily localized internally and TRPC7 located at the cell surface membrane. The data suggest that in photosensitive
RGCs, 2-APB may act at these channels to inhibit the lightevoked response. However, 2-APB can also inhibit melastatin TRP family members (Hu et al., 2004) and volume-regulated anion channels (Lemonnier et al., 2004), and expression of these channels has not been studied in the retina.

\section{2-APB induces acute knockdown of photosensitive RGC activity in vivo}

The evidence suggests that 2-APB is a potent inhibitor of photosensitive RGC activity in vitro. Importantly, we found that this drug is also effective in vivo using the PLR as a functional assay. Intraocular 2-APB application significantly suppressed the PLR. It is unlikely that this effect was caused by a complete inhibition of all RGC activity, because in vitro we observed RGC excitability, independent of the intrinsic light response, in the presence of 2-APB.

The potential applications of this drug are numerous. For example, the function of photosensitive RGC innervations of the intergeniculate leaflet, ventral and dorsal lateral geniculate nucleus, medial amygdala, lateral habenula, and superior colliculus (Hattar et al., 2006) are unknown. 2-APB could be an extremely useful pharmacological tool in elucidating the purpose of photosensitive RGC input to these brain regions. The identification of an acute in vitro and in vivo inhibitor of pRGC activity will certainly help in furthering research in this rapidly expanding field.

\section{References}

Bandyopadhyay BC, Payne R (2004) Variants of TRP ion channel mRNA present in horseshoe crab ventral eye and brain. J Neurochem 91:825-835.

Barnard AR, Hattar S, Hankins MW, Lucas RJ (2006) Melanopsin regulates visual processing in the mouse retina. Curr Biol 16:389-395.

Berson DM, Dunn FA, Takao M (2002) Phototransduction by retinal ganglion cells that set the circadian clock. Science 295:1070-1073.

Dalrymple A, Slater DM, Beech D, Poston L, Tribe RM (2002) Molecular identification and localization of Trp homologues, putative calcium channels, in pregnant human uterus. Mol Hum Reprod 8:946-951.

Hardie RC, Minke B (1992) The trp gene is essential for a light-activated $\mathrm{Ca} 2+$ channel in Drosophila photoreceptors. Neuron 8:643-651.

Hattar S, Liao HW, Takao M, Berson DM, Yau KW (2002) Melanopsincontaining retinal ganglion cells: architecture, projections, and intrinsic photosensitivity. Science 295:1065-1070.

Hattar S, Lucas RJ, Mrosovsky N, Thompson S, Douglas RH, Hankins MW, Lem J, Biel M, Hofmann F, Foster RG, Yau KW (2003) Melanopsin and rod-cone photoreceptive systems account for all major accessory visual functions in mice. Nature 424:76-81.

Hattar S, Kumar M, Park A, Tong P, Tung J, Yau KW, Berson DM (2006) Central projections of melanopsin-expressing retinal ganglion cells in the mouse. J Comp Neurol 497:326-349.

Hu HZ, Gu Q, Wang C, Colton CK, Tang J, Kinoshita-Kawada M, Lee LY, Wood JD, Zhu MX (2004) 2-aminoethoxydiphenyl borate is a common activator of TRPV1, TRPV2, and TRPV3. J Biol Chem 279:35741-35748.

Inoue R, Okada T, Onoue H, Hara Y, Shimizu S, Naitoh S, Ito Y, Mori Y (2001) The transient receptor potential protein homologue TRP6 is the essential component of vascular alpha(1)-adrenoceptor-activated $\mathrm{Ca}(2+)$-permeable cation channel. Circ Res 88:325-332.

Lemonnier L, Prevarskaya N, Mazurier J, Shuba Y, Skryma R (2004) 2-APB inhibits volume-regulated anion channels independently from intracellular calcium signaling modulation. FEBS Lett 556:121-126.

Lucas RJ, Douglas RH, Foster RG (2001) Characterization of an ocular photopigment capable of driving pupillary constriction in mice. Nat Neurosci 4:621-626.

Lucas RJ, Hattar S, Takao M, Berson DM, Foster RG, Yau KW (2003) Diminished pupillary light reflex at high irradiances in melanopsinknockout mice. Science 299:245-247.

Maruyama T, Kanaji T, Nakade S, Kanno T, Mikoshiba K (1997) 2APB, 2-aminoethoxydiphenyl borate, a membrane-penetrable modulator of Ins (1,4,5)P3-induced Ca2 + release. J Biochem (Tokyo) 122:498-505.

Melyan Z, Tarttelin EE, Bellingham J, Lucas RJ, Hankins MW (2005) Addi- 
tion of human melanopsin renders mammalian cells photoresponsive. Nature 433:741-745.

Monk PD, Carne A, Liu SH, Ford JW, Keen JN, Findlay JB (1996) Isolation, cloning, and characterisation of a trp homologue from squid (Loligo forbesi) photoreceptor membranes. J Neurochem 67:2227-2235.

Montell C (2005) The TRP superfamily of cation channels. Sci STKE 2005:re3.

Montell C, Rubin GM (1989) Molecular characterization of the Drosophila trp locus: a putative integral membrane protein required for phototransduction. Neuron 2:1313-1323.

Panda S, Sato TK, Castrucci AM, Rollag MD, DeGrip WJ, Hogenesch JB, Provencio I, Kay SA (2002) Melanopsin (Opn4) requirement for normal light-induced circadian phase shifting. Science 298:2213-2216.

Panda S, Nayak SK, Campo B, Walker JR, Hogenesch JB, Jegla T (2005) Illumination of the melanopsin signaling pathway. Science 307:600-604.

Provencio I, Jiang G, De Grip WJ, Hayes WP, Rollag MD (1998) Melanopsin: an opsin in melanophores, brain, and eye. Proc Natl Acad Sci USA 95:340-345.

Qiu X, Kumbalasiri T, Carlson SM, Wong KY, Krishna V, Provencio I, Berson DM (2005) Induction of photosensitivity by heterologous expression of melanopsin. Nature 433:745-749.
Sekaran S, Foster RG, Lucas RJ, Hankins MW (2003) Calcium imaging reveals a network of intrinsically light-sensitive inner-retinal neurons. Curr Biol 13:1290-1298.

Sekaran S, Lupi D, Jones SL, Sheely CJ, Hattar S, Yau KW, Lucas RJ, Foster RG, Hankins MW (2005) Melanopsin-dependent photoreception provides earliest light detection in the mammalian retina. Curr Biol 15:1099-1107.

Trebak M, Bird GS, McKay RR, Putney Jr JW (2002) Comparison of human TRPC3 channels in receptor-activated and store-operated modes. Differential sensitivity to channel blockers suggests fundamental differences in channel composition. J Biol Chem 277:21617-21623.

Warren EJ, Allen CN, Brown RL, Robinson DW (2006) The light-activated signaling pathway in $\mathrm{SCN}$-projecting rat retinal ganglion cells. Eur J Neurosci 23:2477-2487.

Xu SZ, Zeng F, Boulay G, Grimm C, Harteneck C, Beech DJ (2005) Block of TRPC5 channels by 2 -aminoethoxydiphenyl borate: a differential, extracellular and voltage-dependent effect. Br J Pharmacol 145:405-414.

Zagranichnaya TK, Wu X, Villereal ML (2005) Endogenous TRPC1, TRPC3, and TRPC7 proteins combine to form native store-operated channels in HEK-293 cells. J Biol Chem 280:29559-29569. 